\title{
A NEW SPECIES OF THE GENUS BATASIO BLYTH (TELEOSTEI: BAGRIDAE) FROM MANIPUR, INDIA
}

\author{
W. Vishwanath ${ }^{1}$ and A. Darshan ${ }^{2}$ \\ 1, 2 Department of Life Sciences, Manipur University, Canchipur, Manipur 795003, India \\ Email: ${ }^{1}$ vnath54@yahoo.co.in
}

web supplement

\begin{abstract}
Batasio niger $s p$. nov. is described from Khujailok River, a tributary of Yu River belonging to the Chindwin-Irrawaddy basin in Manipur, India. The new species differs from its congeners (except $\mathrm{B}$. elongatus and $\mathrm{B}$. dayi) in having a black oblique predorsal bar on dark grey to blackish plain body. This species is distinguishable from its closest congeners B. elongatus in having shorter adipose fin base (20.1-27.9\% SL vs. 29.4-35.1), prepectoral length (17.8$23.5 \%$ SL vs. 23.7-27.8), snout length (35.2-39.7\% SL vs. 39.7-44) and relatively deeper body at anus (18.4-24.8\% SL vs. 15.8-19.3); from B. dayi in having wider interorbital distance (29.5-35.3\% HL vs. 25.9-28.6); and from B. tengana in having stouter body (18.4-24.8\% SL vs. 16.4) and more widely-set eyes (interorbital distance $29.5-35.3 \%$ HL vs. 22.2).
\end{abstract}

\author{
KEYWORDS \\ Bagridae, Batasio niger sp. nov., Chindwin-Irrawaddy \\ basin, fish, India, Khujailok River, Manipur, new \\ description
}

\section{Abbreviations}

MUMF - Manipur University Museum of Fishes, Canchipur; ZSI - Zoological Survey of India; Kolkata; SL - Standard Length; TL - Total Length; HL - Head Length.

Small bagrid catfishes of the genus Batasio Blyth are distributed in South and South East Asia. The genus is characteristic in having large sensory pores on head, narrow mental region, a pair of posteriorly directed processes on the anterior part of vomer, transversely elongated bar like entopterygoid, metapterygoid in close contact with quadrate but free from hyomandibular and in absence of ectopterygoid (Mo, 1991).

$\mathrm{Ng}$ and Kottelat (2001) revision of the genus Batasio of Indochinese region included eight species, viz., B. batasio (Hamilton), B. merianiensis (Chaudhuri), and B. tengana (Hamilton) of Ganga-Brahmaputra basin; B. travancoria Hora and Law from Western Ghats, Kerala; $B$. affinis Blyth and $B$. dayi (Vinciguerra) respectively from Tenasserim and Meetan, Myanmar; B. havmolleri (Smith) and a new species, B. tigrinus from Thailand. Ng (2004), Ng and Edds (2004) \& Bhatt and Jayaram (2004) also described B. elongatus from Bew Di Chaung drainage of Myanmar, B. macronotus from Kosi drainage, Nepal and $B$. sharavatiensis from Sharavati River, Karnataka, respectively. Mirza and Jafn (1989) described B. pakistanicus from the Indus River basin. Thus, 12 species of the genus are known so far.

A series of collections were made in the Khujailok stream, draining into the Lokchao River. The Lokchao is a tributary of the Yu River of Myanmar which joins the Chindwin. This region falls within the hotspot area of the Indo-Burmese region. The collections included an undescribed species of the genus Batasio, which is described here as new species. A key to the known species of Batasio is also provided.

\section{Materials And Method}

The specimens were preserved in $10 \%$ formalin and deposited in the Manipur University Museum of Fishes (MUMF). Measurements were made using dial calipers taking nearest to the tenth of a millimeter. Counts and measurements follow $\mathrm{Ng}$ and Kottelat (2001). Numbers in parenthesis following a particular count are the number of specimens examined. Fin rays were counted under stereoscopic microscope under transmitted light. Bones for the study were cleared and stained with alizarin red-S as described by Hollister (1934).

\section{Batasio niger sp. nov.}

(Figure $1 \&$ Image $1^{\mathrm{w}}$ )

\section{Materials examined}

Holotype: 2.iv.2004, Khujailok stream, Chandel district, Manipur, India, 79.1 mm SL, coll. W. Vishwanath and party (MUMF 9028). Paratypes: 7:1 ex., 2.iv.2004, Khujailok stream, Chandel district, Manipur State, India, 89.6mm SL, (MUMF 9025); 1 ex., 12.iv.1996, Moreh market, Chandel district, Manipur State, India, $98.6 \mathrm{~mm}$ SL, (MUMF 9027), both coll. W. Vishwanath and party; 5 exs., 22.ii.2005, Khujailok stream, Chandel district, Manipur State, India, 78.7-93.1mm SL, coll. Th. Hemananda (MUMF 9033).

Etymology

Named after the blackish colouration of the body.

\section{Diagnosis}

Batasio sp. nov. can be differentiated from its congeners in having the following combinations of characters: body with a black oblique predorsal bar on dark grey to blackish plain body, distal half to two thirds of dorsal fin blackish, interorbital distance $29.5-35.3 \% \mathrm{HL}$, snout length 35.2-39.7\% HL, adipose fin base $20.1-27.9 \%$ SL, prepectoral length $17.8-23.5 \%$ SL and body depth at anus $18.4-24.8 \%$ SL.

\section{Description}

Body and head laterally compressed. Tip of snout small and rounded, projecting over the mouth. Dorsal profile rising somewhat steeply from tip of snout to the origin of dorsal fin then sloping gently ventrally towards caudal peduncle. Ventral profile roughly horizontal from end of opercle to the origin of

w See Image 1 in the web supplement at www.zoosprint.org

(C) Zoo Outreach Organisation; www.zoosprint.org

Manuscript 1426; Received 29 August 2005; Revised received 23 December 2005; Finally accepted 10 January 2006 ; Date of publication 21 January 2006 

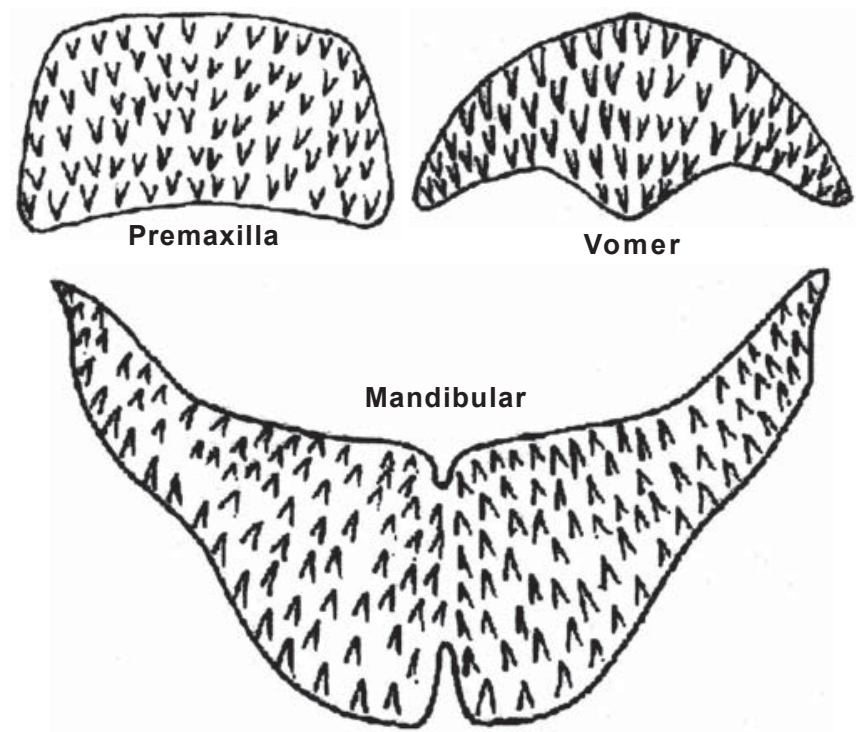

Figure 1. Dentition of Batasio niger sp. nov. (MUMF 9027, 98.6mm SL)

anal fin then sloping dorsally towards caudal peduncle. Occipital process reaches basal bone of dorsal fin. It has a shallow median depression and forks at the posterior tip for articulation to anteriorly pointed predorsal bone. Median longitudinal groove on head reaching base of occipital process. Orbit with free margin located on the dorsal half of head, not visible from the ventral side. Body depth varies greatly (18.4 to $24.8 \% \mathrm{SL}$ ) in the species. Mouth inferior. Lips fleshy, fimbriated and continuous at the angle of mouth. Premaxillary tooth band roughly semicircular with 5-6 rows of teeth, of which first one or two anterior rows exposed when mouth is closed. Teeth villiform and in irregular rows on all teeth bearing surface. Vomerine tooth band continuous, length twice its width, anteriorly convex, laterally tapering to a point and posterior margin protruded medially. Dentary tooth band broader than premaxillary and vomerine at symphysis, posterolaterally tapering reaching the angle of mouth. Anterior nostril tubular with two small openings at its base, one dorsally and another ventrally. Gill membranes free from isthmus and not overlapping. Gill opening wide extending from postemporal to beyond isthmus. Branchiostegal rays 6(8). Gill rakers short and $2+7=$ 9(3) on the first branchial arch.

Four pairs of barbels; maxillary - reaching posterior border of eye, nasals - flat dorsoventrally at base and cross anterior border of eye, but not extending to middle of eye. Inner mandibular barbels minute and short. Outer mandibular longer and lies posterolaterally to inner mandibular barbel. Five large pores between the lower lip and pair mandibular barbels. The middle one posterior to the other four is a fused structure of two closely lying pores, often distinctly separated, inserted slightly anterior to the mid-point between the two inner mandibular barbels.

Dorsal fin with spinelet, spine and 7(8) rays. Dorsal origin nearer tip of snout than the caudal flexure. Posterior distal half of dorsal spine feebly serrated. Depressed dorsal reaches origin
Table 1. Morphometric data of Batasio niger sp. nov.

\begin{tabular}{llll}
\hline & Mean & Range & \pm S.D \\
\hline Percentages SL & & & \\
Head length & 23.4 & $20.6-26.5$ & \pm 1.8 \\
Head wide & 14.1 & $13.0-16.6$ & \pm 3.0 \\
Head depth & 19.4 & $16.7-22.3$ & \pm 1.8 \\
Pre dorsal distance & 37.2 & $32.7-42.2$ & \pm 2.9 \\
Pre anal length & 68.7 & $58.3-72.2$ & \pm 4.4 \\
Pre pelvic length & 51.8 & $46.0-57.6$ & \pm 3.3 \\
Pre pectoral length & 21.3 & $17.8-23.5$ & \pm 1.8 \\
Body depth at anus & 20.5 & $18.4-24.8$ & \pm 2.2 \\
Length of caudal peduncle & 17.8 & $13.3-19.9$ & \pm 2.1 \\
Depth of caudal peduncle & 10.5 & $9.2-11.8$ & \pm 0.9 \\
Pectoral fin length & 17.9 & $13.5-21.4$ & \pm 2.2 \\
Pectoral spine length & 12.5 & $11.4-13.8$ & \pm 0.9 \\
Length of dorsal fin base & 13.2 & $9.9-14.9$ & \pm 1.5 \\
Dorsal spine length & 12.5 & $10.5-13.6$ & \pm 1.3 \\
Pelvic fin length & 13.9 & $11.3-16.2$ & \pm 1.5 \\
Length of anal fin base & 12.3 & $9.2-13.7$ & \pm 1.5 \\
Caudal fin length & 22.2 & $17.7-26.7$ & \pm 2.5 \\
Length of adipose fin base & 25.4 & $20.1-27.9$ & \pm 2.9 \\
Dorsal to adipose distance & 8.5 & $5.8-10.8$ & \pm 1.7 \\
Percentages HL & & & \\
Snout length & & & \\
Interorbital distance & 36 & $35.2-39.7$ & \pm 2.6 \\
Eye diameter & 31.8 & $29.5-35.3$ & \pm 2.3 \\
Nasal barbel & 23.9 & $20.9-28.6$ & \pm 2.8 \\
Maxillary barbel length & 18.6 & $16.8-19.8$ & \pm 1.3 \\
Inner mandibular barbel length & 46.1 & $41.1-53.2$ & \pm 5.1 \\
Outer mandibular barbel length & 15.7 & $7.5-22.9$ & \pm 7.1 \\
\hline & & $13.3-17.8$ & \pm 2.5 \\
\hline
\end{tabular}

of adipose fin. Adipose fin short and its origin lies slightly posterior to the opposite position of vent giving a distinct interdorsal gap. Pectoral fin with a spine and 8(7) or 9(1) branched rays. Pectoral spine stout with sharp pointed tip and large $8(1)$ or $9(1)$ or $10(2)$ or 11(4) serrations on posterior edge. Pelvic fin rays with i, 5(8) rays. Depressed pelvic fin reaches urinogenital opening or extends up to anal origin. Anal fin with iii, 8(2), iii, 9(5) or iv, 9(1) rays, lies at the level of the dorsally sloping portion Caudal fin forked with i, 7, 8, i (8) rays; upper lobe slightly longer. Procurrent rays with $17(2)$ or $18(1)$ on upper lobe and 15(1) or 16(2) rays on the lower lobe. Caudal plate with five hypural plates, third and fourth fused together. Primary and secondary hypuropophysis fused.

Skin smooth with dark grey pigments scattered all over the body including the barbels and the fin rays. Lateral line complete and midlateral. Vertebra: $20+20=40(3)$.

\section{Colour}

Live or fresh specimens have dark grey to blackish body with a black oblique predorsal bar. A small indistinct additional bar may be seen at the posterior dorsal base in a few specimens. The predorsal bar originates from the predorsal bone and runs obliquely backwards reaching the lateral line. In some specimens the predorsal bar may be indistinct. Colour of adipose fin is similar to that of body. Belly dirty white with sparsely scattered fine melanophores. Distal half to two thirds of dorsal fin blackish due to heavy concentrations of melanophores on the rays and interradial membranes. Rays of pectoral, pelvic, anal and caudal are dotted with melanophores but interradial membranes are clear. In 10\% formalin, body colour appears to be brownish-grey with faint or dark brown 
oblique predorsal bar.

\section{Distribution}

Presently known from Khujailok stream (Chindwin drainage) Manipur State, India.

\section{Discussion}

Batasio niger sp. nov. is similar to B. elongatus and B. dayi in having an oblique predorsal bar. But it differs from B. elongatus in having a relatively deeper body at anus (18.4-24.8\% SL vs. 15.8-19.3), shorter prepectoral length (17.8-23.5\% SL vs. 23.727.8), shorter adipose fin base length (20.1-27.9\% SL vs. 29.435.1), shorter snout length (35.2-39.7\% HL vs. 39.7-44.9), nasal barbel (16.8-19.8 \% HL vs. 19.1-41.3) and mandibular barbel (13.3-17.8\% HL vs. 22.8-32.4), low gill rakers count $(2+7=9$ vs. $5-6+14-21=20-27)$, fewer branchiostegal rays (6 vs. 9-10) and higher vertebral count (40 vs.36-38). Only the distal half to two thirds of dorsal fin is blackish in the new species but in $B$. elongatus, there are two crescentic brown bands, one on the distal quarter and another on the base of dorsal fin.

Batasio niger sp. nov. is distinct from $B$. dayi in having wider interorbital distance (29.5-35.3\% HL vs. 25.9-28.6); in having distal half to two thirds of dorsal fin blackish vs distal four- fifths of dorsal fin dark brown. B. dayi is also distinct in having a narrow hyaline distal margin. $B$. niger has a shorter adipose fin base than B. dayi as in Fig. 3 of $\mathrm{Ng}$ and Kottelat (2001), i.e., 20.1-27.9\% SL vs. 28.4 and 19.8-24.5\% TL vs. 32.3 (Vinciguerra, 1890).

It also differs from $B$. tengana in having deeper body at anus (18.4-24.8\% SL vs. 16.4) and more widely set eyes (interorbital distance 29.5-35.3\% SL vs. 22.2). Ng and Kottelat (2001) examined B. tengana (UMMZ 209009) and found to have a dark vertical bar on the dorsal half of the body in front of the dorsal fin terminating in an elliptical spot below the dorsal fin. They reported the dark area above the pectoral fin to be the portion of upper half of air bladder. However, Bhatt and Jayaram (2004) reported $B$. tengana to have five broad bands, descending from the dorsal surface to the lateral line. They commented that the specimen observed by $\mathrm{Ng}$ and Kottelat (2001) might have been faded due to long preservation, but insisted the specimen to have a distinct humeral spot. In the key provided in this paper, we consider description by Bhatt and Jayaram (2004) with five broad bands on body. Examination of fresh specimens of the species will be required to provide a better description of the species. The new species also differs from $B$. affinis in having shorter adipose fin base $(20.1-27.9 \%$

\section{Key to known species of genus Batasio}

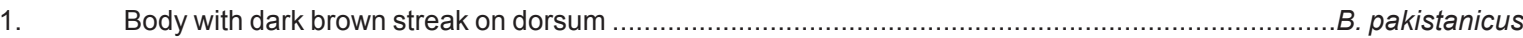

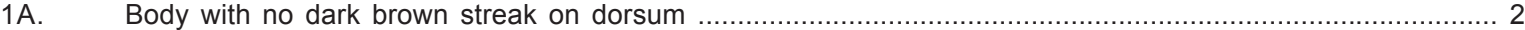

2. Body plain, a narrow notch between adipose fin and caudal fin ..................................... B. saravantiensis

2A. $\quad$ Body with bar or stripe, a distinct gape between adipose fin and caudal fin .........................................

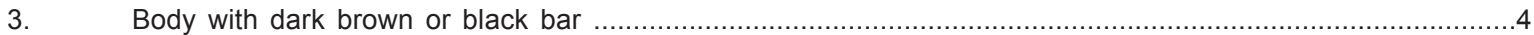

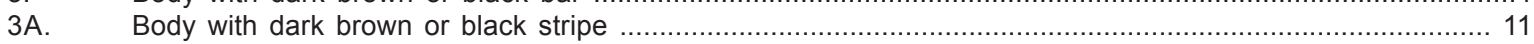

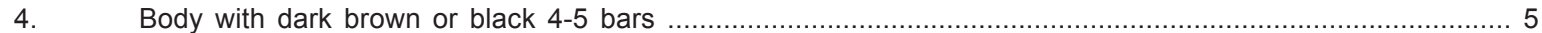

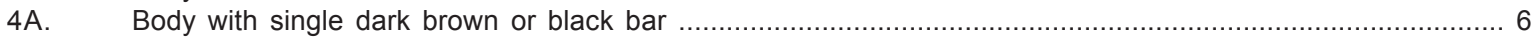

5. Body with four bars, anteriormost bar passing through eyes, body deep, its depth at anus $18.4-20.8 \% \mathrm{SL}$; eyes far apart, interorbital distance 29.3-31.9 \% HL .................................................................. B. tigrinus

5A. Body with five broad bars; body shallow, its depth $16.4 \% \mathrm{SL}$; eyes closely set, iterorbital distance $22.2 \% \mathrm{HL}$

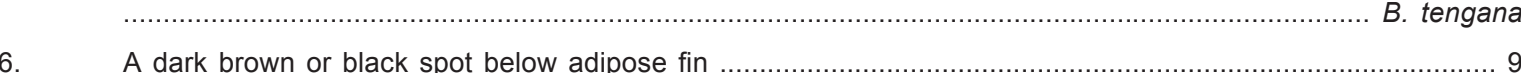

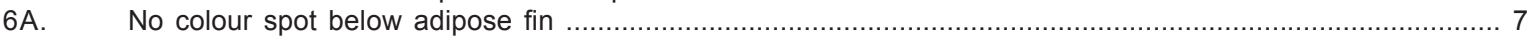

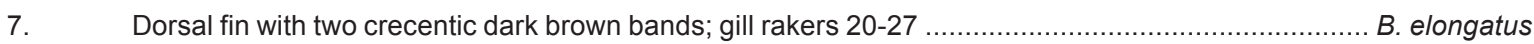

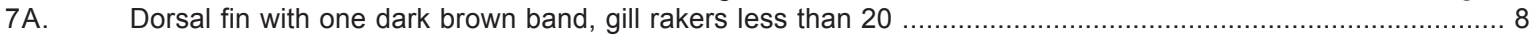

8. Distal fourth fifth of dorsal fin dark brown; eyes closely set, interorbital space $25.9-28.6 \% \mathrm{HL}$ )......... B. dayi 8A. Distal half to two third of dorsal fin blackish; Interorbital space wide, $29.5-35.3 \% \mathrm{HL} \ldots \ldots \ldots \ldots$. B. niger sp. nov.

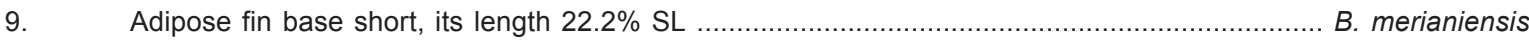

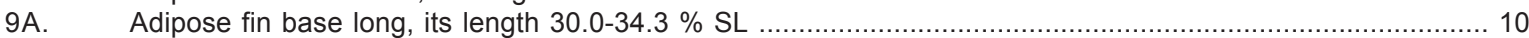

10. Pelvic origin in front of base of last dorsal fin ray, distal one third of dorsal fin dark brown with a narrow hyaline

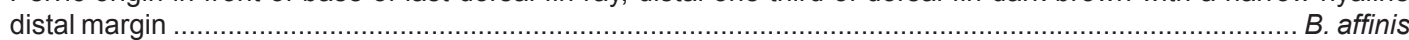
Pelvic origin below or slightly behind last dorsal fin ray, distal one third of dorsal fin dark brown with a narrow hyaline distal margin ........................................................................................................... havmolleri

11. One mid-lateral dark brown stripe along lateral line, a triangular mark at the posterior edge of caudal peduncle

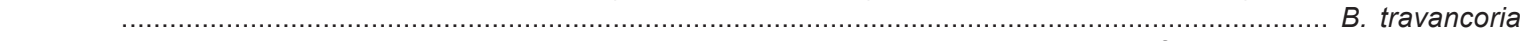

11A. Two lateral dark brown stripes on body, no triangular mark at the posterior edge of caudal peduncle ........... 12

12. Dorsal spine long, its length $16.7-18.5 \% \mathrm{SL}$, adipose fin base short, its length (24.8-26.5 \% SL), body depth at anus 17.0-17.4 \% SL ........................................................................................................... B. batasio

12A. Dorsal spine short, its length $14.0-16.1 \% \mathrm{SL}$, adipose fin base long, its length $28.3-31.8 \%$ SL, body depth at anus $19.5-21.2 \%$ SL ....................................................................................................... B. macronotus 
SL vs. 34.3) and pectoral spine (11.4-13.8\% SL vs. 14).

Batasio niger sp. nov. is also easily distinguished from $B$. sharavatiensis by its blackish predorsal bar vs. plain colourless body and short adipose fin which terminates far ahead of the caudal fin base vs. long adipose fin, almost confluent (Bhatt \& Jayaram (2004) diagnosis) with the caudal fin but for a narrow notch.

ZSI specimen from Chendero Lake, Perak, Malaysia (ZSI F120/ 2) labeled as B. tengana differs from $\mathrm{Ng}$ and Kottelat's (2001) description of $B$. tengana in having deeper body at anus $(19.2 \%$ SL vs. 16.4) and wider interorbital distance (28.5\% HL vs. 22.2). The specimen has the characteristic predorsal bar along with a dark brown spot on the sides below adipose fin and also the proportional measurements as of $B$. havmolleri. The type locality of $B$. tengana is Brahmaputra basin while that of $B$. havmolleri is Thailand. Occurrence of B. tengana in Malaysia is unlikely.

The new species also differs from B. havmolleri? (ZSI F120/2, $50.5 \mathrm{~mm} \mathrm{SL})$ in having narrower head (13.0-16.6\% SL vs. 17.7), shorter preanal length (58.3-72.2\% SL vs. 73.1), adipose fin base (20.1-27.9\% SL vs. 29.8), snout (35.2-39.7\% HL vs. 41.4) and anal fin base (9.2-13.7\% SL vs. 14.1).

Batasio pakistanikus was described from Indus-river basin by Mirza and Jafn (1989). Ng and Kottelat (2001), and Bhatt and Jayaram (2004) doubt its generic placement. However, presents of humeral spot in this species clearly differentiates from the new species which lacks this spot.

\section{REFERENCES}

Bhatt, A. and K.C. Jayaram (2004). A new species of the genus Batasio Blyth (Siluriformes: Bagridae) from Sharavati River, Uttara Kannada, Karnataka. Zoos' Print Journal 19(2): 1339-1342.

Hollister, G. (1934). Clearing and dyeing fishes for bone study. Zoologica 12: 89-101.

Mirza, M.R. and M.A. Jafn (1989). Batasio pakistanicus new species, a new catfish (Pisces, Bagridae) from Pakistan. Science Khyber 2(2): 283-286.

Mo, T. (1991). Anatomy, relationships and systematics of Bagridae (Teieostei: Siluroidei) with a hypothesis of siluroid phylogeny. Thesis Zoologicae 17:1-216.

Ng, H.H. and D.R. Edds (2004). Batasio macronotus, a new species of bagrid catfish from Nepal (Teleostei: Bagridae). Ichthyological Exploration of Freshwater 15(4): 295-300, 7 figs., 1 tab.

Ng, H.H. and M. Kottelat (2001). A review of the genus Batasio (Teleostei: Bagridae) in Indochina, with the description of $B$. tigrinus sp. n. from Thailand. Revue de Suisse Zoologie 108(3): 495-511.

Ng, H.H. (2004). Batasio elongatus, a new species of bagrid catfish from Southwest Myanmar (Siluriformes: Bagridae). Ichthyological Exploration of Freshwater 15(1): 67-70, 3 figs., 1 tab..

Vinciguerra, D. (1890). Viaggo di Leonardo Fea in Birmania e regioni vicini. XXIV. Pesci. Annali del Museo Civico Storia Naturale di Genova 9: 129-362, pls 7-11.

Comparative Material. Batasio tengana (havmolleri ?): ZSI F120/2, 50.5 mm SL; Chendero Lake, Perak, F.M.S. Collection of Raffles Museum.

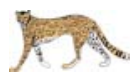

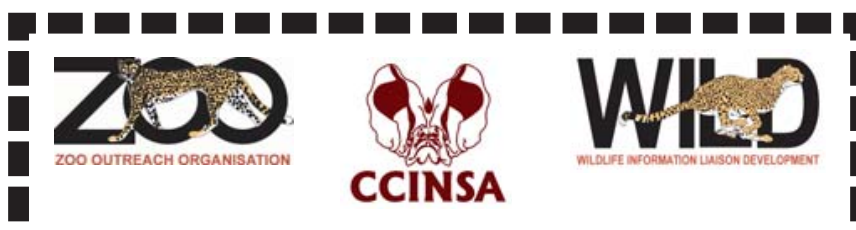

South Asian
Bat Monitoring Programme

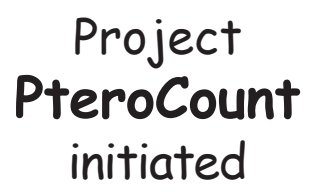

If you are interested in volunteering for this exciting project, please visit us at www.pterocount.org or write to us

Volunteers who have enrolled can visit www. pterocount.org for more details. Individual mailers are being sent to all participants with an Overview and Data Form

Project PteroCount c/o CCINSA, ZOO, WILD 29-1 Bharathi Colony, Peelamedu Coimbatore, Tamil Nadu 641004 India

Email: contact@pterocount.org pterocount@yahoo.com
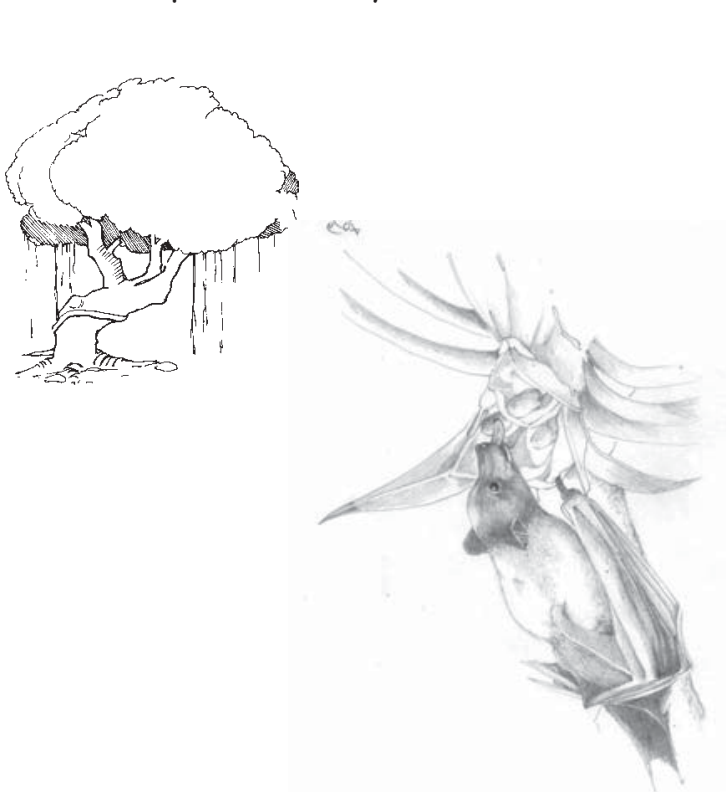